Chapter 10

\title{
Psychogenic Non-Epileptic Seizures in a Surgical Epilepsy Unit: Experience and a Comprehensive Review
}

\author{
Lorena Vega-Zelaya, Marta Alvarez, Elena Ezquiaga, \\ Jaime Nogeiras, María Toledo, Rafael G. Sola and \\ Jesús Pastor
}

Additional information is available at the end of the chapter

http://dx.doi.org/10.5772/57439

\section{Introduction}

Psychogenic non-epileptic seizures (PNES) are paroxysmal involuntary changes in behaviour, sensation, motor activity, cognitive processing or autonomic function that resemble epileptic seizures (ES). However, they have no electrophysiological correlate but instead possess a psychological origin [1, 2].

Historically known as hysteria seizures by Hippocrates and Aristotle, the French neurologist Jean-Martin Charcot recognised hysteria as a neurologically diagnosable condition. Many years after this recognition, Sigmund Freud reclassified hysteria as a psychiatric disorder.

Previously, PNES has been given various names, such as pseudoseizures, non-epileptic spells or psychogenic seizures. In general, this terminology involving the prefix 'pseudo-' has become out-dated as it implies that the seizures are not real and may suggest 'malingering'.

PNES have been commonly classified as dissociative or conversion disorders. However, PNES have also been considered to be very similar to other functional somatic symptoms and syndromes [3]. In the current and recently published DSM-V, PNES are classified as a "functional neurological symptom disorder". It appears that PNES are not a single entity and that a variety of clinical manifestations can occur. Furthermore, comorbid psychiatric disorders are common; thus, it is not surprising that a PNES diagnosis is difficult to achieve. PNES exist at the interface of neurology and psychiatry and as discussed below, constitute an important challenge in the practice of both medical specialties, because of their inherent diagnostic and therapeutic difficulties. 
Misdiagnosis leads to iatrogenic effects of antiepileptic medication and aggressive or invasive procedures, such as intubations during emergency department visits [4]. After initial symptom onset, the average time to a formal PNES diagnosis is 7 to 9 years $[2,4,5]$.

Video-electroencephalography (vEEG) monitoring is an indispensable tool for diagnosing PNES because it allows the simultaneous analysis of both clinical and ictal EEG findings. In some cases, provocative techniques aid in diagnosing PNES, and these are performed only when necessary and in approximately $30-50 \%$ of patients diagnosed with PNES [6]. These techniques are very useful in detecting the presence of suggestibility, which strongly supports a psychogenic mechanism.

Approximately $25-30 \%$ of epilepsy patients referred to tertiary epilepsy centres or specialised hospitals have PNES [7]. The incidence of PNES is approximately $4 \%$ of the total epilepsy incidence [8], and in fact, most patients misdiagnosed with epilepsy at epilepsy centres have PNES [9]. These patients are heavy users of emergency and nonemergency health care [10], and approximately three fourths receive inappropriate AED treatment before their diagnosis [11], which can produce adverse side effects, high costs to health care facilities, high medical utilisation rates and high personal and societal costs.

At present, PNES are considered symptoms of an underlying psychological or psychiatric disorder and are associated with impaired social function [12] and high disability [13, 14] that affect patient quality of life $[15,16]$. Disability and quality of life may even be poorer than in epilepsy patients $[12,14,17]$. Additionally, PNES patients have been reported to be twice as likely to be unemployed as patients with epilepsy [12].

PNES seem to occur more frequently in women [18] but also may be more difficult to recognise in men [19]. Gender differences in clinical presentation have been reported, and males have shown higher seizure frequencies, more antiepileptic drug use, and a longer interval before PNES diagnosis [12]. Most patients experienced PNES onset at a young age, and approximately $10 \%$ of patients experienced PNES onset after the age of 60 [20].

Furthermore, patients from lower sociocultural classes are more likely to experience PNES [4]. A small number of clinical studies have observed differences in the cognitive profiles of patients with PNES versus patients with epilepsy [21].

A PNES diagnosis is a very common and important diagnosis in epilepsy units and is described as a common condition associated with epilepsy (PNES+ E). In this study, we attempted to depict and describe the characteristics of PNES patients and the difficulty of diagnosis in a national referral centre for epilepsy surgery. In light of the current literature, the physiopathological hypothesis, treatment and prognosis should be revised.

\section{Methods}

\subsection{Patients}

We retrospectively reviewed all patients with an intractable epilepsy diagnosis admitted to the National Referral Centre for Epilepsy Surgery at the Hospital Universitario de la Princesa 
between July 2001 and July 2013. All patients underwent prolonged video-electroencephalography (vEEG) monitoring as part of the evaluation for surgical treatment [22, 23]. The evaluation also included psychiatric, psychological and clinical evaluations, scalp EEG, 1.5T magnetic resonance imaging (MRI) and interictal single photon emission-computed tomography (SPECT) with ${ }^{99 \mathrm{~m} T c-H m P A O}$. vEEG monitoring was conducted using 19 collodion-fixed scalp electrodes, according to the international 10-20 system. During vEEG recordings, antiepileptic drugs were progressively removed from the second to the fourth day of recordings at a rate of approximately one-third of the dose per day. The digital EEGs (NeuroWorks, XLTEK®, Oakville, Canada) were sampled at $512 \mathrm{~Hz}$ and filtered at $0.5-70 \mathrm{~Hz}$ with a notch filter of $50 \mathrm{~Hz}$. Accessory electrodes were used to monitor electromyography (EMG) at different muscles in combination with an electrocardiogram (EKG).

The following criteria were used to diagnose PNES: (1) at least one single typical clinical event captured on vEEG, (2) the EEG recording did not detect any concomitant ictal activity or postictal slowing, and (3) no evidence of any alternative neurological diagnosis (e.g., movement disorders) [3]. An epilepsy diagnosis was assigned according to the International League Against Epilepsy (ILAE) classification system [24]. The provocative protocol technique with placebo was utilised in cases where discordance was observed between the clinical and electrical findings.

\subsection{Induction techniques}

We used induction techniques to support the diagnosis of PNES when considered useful [25]. The systematic steps in the provocative induction technique with placebo utilised in our epilepsy unit were [26]:

All patients received verbal information and signed an inform consent document stating the need for a test with a drug that could induce their seizures. The informed consent was accepted by the Hospital's ethical committee.

Two neurophysiologists were present and monitored the entire study.

Bioelectrical brain function and behaviour was simultaneously monitored by vEEG.

The following cardiorespiratory parameters were monitored: EKG, respiratory rate, capillary saturation oxygen $\left(\mathrm{SaO}_{2}\right)$ and blood pressure.

Two millilitres of a saline solution were intravenously injected. When a typical seizure appeared, a second 2-ml bolus of saline was administered to terminate the event.

Psychiatric assessment

Diagnoses were determined according to the DSM-IV-TR criteria (Diagnostic and Statistical Manual of Mental Disorders, fourth edition, text revision, Axis I Disorders).

All patients were evaluated with a non-structured clinical assessment interview according to the Protocol of Psychiatric Assessment for our Epilepsy Surgery Unit (Table 1). 
The psychiatric assessment of all patients included the following:

Mental health exploration to identify current psychiatric disorders.

History of psychiatric disorders.

Personality traits.

History of drug abuse and previous and current psychopharmacologic treatments, including benzodiazepines, antidepressants and antipsychotic drugs.

Previous abuse or childhood trauma.

A neuropsychological assessment including IQ, verbal and manipulative IQ, total, verbal and visual memory and executive function tests.

Table 1. Patient psychiatric assessment

\subsection{Statistical analysis}

Statistical comparisons between groups were performed using Student's t-test (two groups) or analysis of variance (more than two groups) for parametric samples. For non-parametric samples, the Mann-Whitney test (two groups) and the Kruskal-Wallis test (more than two groups) were used. The sample fit to a Gaussian distribution was assessed by the chi-square or Kolmogorov-Smirnov tests.

The SigmaStat 3.5 software (SigmaStat, Point Richmond, CA, USA) was used for the statistical analysis. The significance level was set at $p<0.05$. The results are presented as the mean $\pm S E M$, except where otherwise indicated.

For patients in whom differential diagnosis was especially difficult, a numerical analysis of EEG recordings was performed to differentiate between epilepsy and PNES by developing a custom program with Matlab R2008 software (MathWorks, Natic, USA).

Recordings of bioelectrical activity occurring prior to the seizure and during the epileptic event were exported as ASCII files for analysis. For every channel, a Butterworth digital filter from 0,5 to $70 \mathrm{~Hz}$ (notch filter, $48-52 \mathrm{~Hz}$ ) was applied. Artefact free periods of 5 to $10 \mathrm{~s}$ were divided in $N$ non-overlapping windows of 1024 points each, and no software was used to remove electrooculogram signals. We calculated the fast Fourier transform (FFT) for every channel $\left(X_{i} ; \mathrm{i}=1,2, \ldots 19\right)$. The power spectrum $\left(S_{i} ; \mathrm{i}=1,2, \ldots 19\right)$ was divided into the EEG frequency bands delta $(0.5-4 \mathrm{~Hz})$, theta $(4-8 \mathrm{~Hz})$, alpha $(8-13 \mathrm{~Hz})$ and beta $(13-30 \mathrm{~Hz})$, and the total area under the curve was computed. $\left(S_{i, k} ; i=1,2, \ldots 19 ; k=1,2, \ldots N\right)$. Cross-spectra between channels $i$ and $j$ $\left(S_{i j}\right)$ were also calculated for all channel pairs. Coherence [27] for the frequency, $\mathrm{f}$, and for every channel pair, $i$ and $j$, is defined according to the following expression:

$$
C(f)=\frac{\left|\left\langle S_{i j}(f)\right\rangle_{N}\right| 2}{\left\langle S_{i i}(f)\right\rangle_{N}\left\langle S_{i j}(f)\right\rangle_{N}}
$$

Local coherence $(c)$ was obtained from neighbouring channels according to the following expression [28]: 


$$
c(f)=\frac{1}{p} \sum_{i=1}^{p} C_{i}
$$

Where $p$ is the number of electrodes that were computed.

Statistical comparisons between each channel before and during seizures were performed.

\section{Results}

\subsection{Patient classifications}

A total of 630 patients were included in this study. We classified the patients into 4 diagnostic groups according to the following criteria (Table 2) [26]:

- Epilepsy: clinical and bioelectrical evidence of epileptic seizures were confirmed. We did not distinguish between partial and generalised epilepsy because that classification was outside the scope of this work.

- No evidence of seizures: in these cases, the data suggested epilepsy (abnormal epileptiform activity in the vEEG), but no seizures occurred after a sufficient period of time without medication (usually more than 2 weeks).

- No evidence of epilepsy: no epileptiform activity or any clinical event was observed during vEEG recordings that supported a PNES or epilepsy diagnosis.

- PNES: at least one typical clinical event was captured on vEEG but without concomitant epileptiform bioelectric characteristics or other justifiable organic causes.

\begin{tabular}{lll}
\hline & $\mathbf{n}$ & $\%$ \\
\hline Epilepsy & 554 & 87,9 \\
\hline No evidence of seizures & 23 & 3,7 \\
\hline No evidence of epilepsy & 23 & 3,7 \\
\hline PNES & 30 & 4,7 \\
\hline
\end{tabular}

Table 2. Diagnostic classifications of patients.

We analysed the clinical features of PNES and epilepsy patients. The mean age of the PNES patients was 33,9 $\pm 1,7$ years old, and the mean age of epileptic patients was 34,3 $\pm 0,5$ years old ( $p<0,05$, Student's $t$ test). The average age of seizure onset was 15,6 $\pm 2,0$ years old for PNES patients and 11,9 $\pm 0,4$ years old for epilepsy patients (n.s., Student's t test).

The mean seizure frequency for epileptic and PNES patients is shown in Figure 1. 


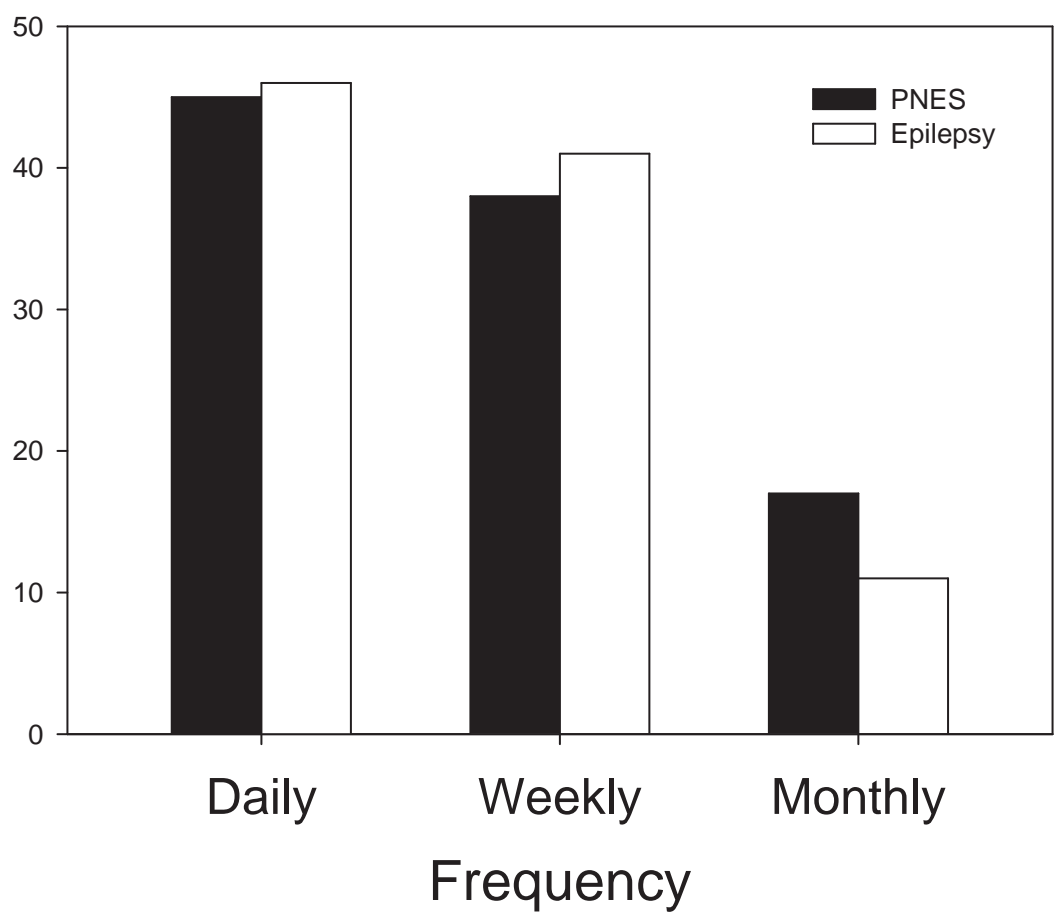

Figure 1. Mean seizure frequency for PNES (filled bars) and epileptic patients (empty bars).

Females represented a greater percentage of PNES patients (20/30). In addition, 70\% of PNES patients presented with comorbid epilepsy (PNES+E, 12/21) or epileptiform activity (PNES +EA, 9/21), which were verified by EEG recordings (Table 3). Nine of the 30 patients were diagnosed with PNES alone.

\begin{tabular}{|c|c|c|c|c|c|c|c|c|}
\hline $\begin{array}{l}\text { Patient } \\
\text { Number }\end{array}$ & $\begin{array}{c}\text { Age } \\
\text { (years) }\end{array}$ & $\begin{array}{l}\text { Age of } \\
\text { Onset } \\
\text { (years) }\end{array}$ & SPECT & MRI & vEEG & $\begin{array}{l}\text { Engel's } \\
\text { scale }\end{array}$ & $\begin{array}{l}\text { Placebo/ } \\
\text { Response }\end{array}$ & $\begin{array}{l}\text { Psychiatric } \\
\text { Disorder(s) }\end{array}$ \\
\hline 1 & 18 & 18 & Normal & Normal & & - & & PTSD \\
\hline 2 & 31 & 7 & Normal & Normal & & - & & DS \\
\hline 3 & 30 & 2 & $\mathrm{Bi}-\mathrm{T}$ & Tuberose Sclerosis & L-T AE & - & Yes/Yes & DS \\
\hline 4 & 29 & & $\mathrm{Bi}-\mathrm{T}$ & Normal & $\begin{array}{l}\text { Petit mal } \\
\text { Epilepsy }\end{array}$ & - & & Anxiety \\
\hline 5 & 19 & 1 & $\mathrm{Bi}-\mathrm{T}$ & Bi-TMS & L-T AE & - & Yes/No & No \\
\hline 6 & 19 & 16 & Bi-T & $\begin{array}{c}\text { Multiple } \\
\text { cavernomas }\end{array}$ & L-TLME & - & & Dysthymia \\
\hline
\end{tabular}




\begin{tabular}{|c|c|c|c|c|c|c|c|c|}
\hline $\begin{array}{l}\text { Patient } \\
\text { Number }\end{array}$ & $\begin{array}{c}\text { Age } \\
\text { (years) }\end{array}$ & $\begin{array}{l}\text { Age of } \\
\text { Onset } \\
\text { (years) }\end{array}$ & SPECT & MRI & vEEG & $\begin{array}{l}\text { Engel's } \\
\text { scale }\end{array}$ & $\begin{array}{l}\text { Placebo/ } \\
\text { Response }\end{array}$ & $\begin{array}{l}\text { Psychiatric } \\
\text { Disorder(s) }\end{array}$ \\
\hline 7 & 47 & 9 & $\mathrm{Bi}-\mathrm{T}$ & $\begin{array}{c}\text { Subcortical } \\
\text { Hyperintensities }\end{array}$ & R-T AE & - & & No \\
\hline 8 & 37 & 8 & L-T & Normal & GE & - & Yes/Yes & No \\
\hline 9 & 19 & 16 & Normal & Normal & & - & Yes/No & DS \\
\hline 10 & 55 & 3 & R-MT & Normal & Bi-T EA & - & Yes/Yes & No \\
\hline 11 & 37 & 31 & Normal & Normal & L-TLE & II & & Anxiety \\
\hline 12 & 33 & 3 & $\mathrm{Bi}-\mathrm{T}$ & Surgical changes & Bi-T EA & - & Yes/Yes & No \\
\hline 13 & 32 & 3 & $\begin{array}{l}\text { Irregular } \\
\text { perfusion }\end{array}$ & $\begin{array}{c}\text { R-F } \\
\text { Encephalomalacia }\end{array}$ & R-FLE & & Yes/Yes & No \\
\hline 14 & 49 & 26 & R-MT & R-MTS & R-MTLE & I & Yes/Yes & No \\
\hline 15 & 28 & 15 & Normal & Normal & & - & & DS \\
\hline 16 & 35 & 30 & L-T & $\begin{array}{l}\text { L-T anterior horn } \\
\text { increase }\end{array}$ & & - & & No \\
\hline 17 & 49 & 35 & R-MT & $\begin{array}{l}\text { R-T anterior horn } \\
\text { increase }\end{array}$ & R-T EA & - & & Depression \\
\hline 18 & 41 & 28 & L-T & L-MTS & L-T EA & _- & & Depression \\
\hline 19 & 37 & 14 & $\mathrm{Bi}-\mathrm{FT}$ & $\begin{array}{l}\text { Bi-FP ischemic } \\
\text { alterations }\end{array}$ & & - & & No \\
\hline 20 & 40 & 1 & L-TM & Normal & G- EA & - & & No \\
\hline 21 & 16 & 13 & L-MT & L-MTS & & - & Yes/Yes & No \\
\hline 22 & 33 & 14 & R-MT & Normal & & - & & No \\
\hline 23 & 41 & 27 & L-FP & Normal & & - & & No \\
\hline 24 & 40 & 23 & $\begin{array}{l}\text { Irregular } \\
\text { perfusion }\end{array}$ & $\begin{array}{l}\text { L Hippocampal } \\
\text { dysplasia }\end{array}$ & L-T EA & - & & Anxiety \\
\hline 25 & 32 & 8 & L-FT & R-MTS & L-FLE & I & & Depression \\
\hline 26 & 38 & 29 & R-MT & Normal & L-MTLE & - & & No \\
\hline 27 & 35 & 2 & L-MT & L-MTS & L-MTLE & I & & Anxiety \\
\hline 28 & 48 & 23 & R-MT & Normal & L-MTLE & I & & Anxiety \\
\hline 29 & 27 & 1 & R-MT & R-MTS & R-MTLE & - & & No \\
\hline 30 & 33 & 20 & $\mathrm{Bi}-\mathrm{F}$ & $\begin{array}{c}\text { R-F Hyper-intensities } \\
\text { WM }\end{array}$ & L-MTLE & - & & Depression \\
\hline
\end{tabular}

Table 3. Characteristics of PNES patients.

Bi, bilateral; DS, dissociative disorders; EA, epileptiform activity; F, frontal; FLE, frontal lobe epilepsy; FP, fronto-parietal; FT, fronto-temporal; GE, generalised epilepsy; L, left; MT, mesial temporal; MTLE, mesial temporal lobe epilepsy; MTS, mesial temporal sclerosis; PTSD, posttraumatic stress disorder; $\mathrm{R}$, right; $\mathrm{T}$, temporal; TLE, temporal lobe epilepsy; WM, white matter. 
The semiology of PNES was highly stereotyped in each patient and mainly consisted of convulsive components or bizarre bilateral motor manifestations involving the upper or lower limbs. Other manifestations lacked motor events but involved sensory feelings or unresponsiveness, although these stereotypies were less frequent.

Importantly, in the PNES+E group, structural abnormalities were evident in 11/12 neuroimaging studies. We also found that in patients diagnosed as PNES+EA, structural abnormalities associated with temporal lobe epilepsy were observed in 9 patients. Moreover, 3 patients presented with mesial temporal sclerosis in MRI studies.

When we assessed the PNES group with the same tests, we found that there were cerebral perfusion abnormalities on SPECT in 6/9 patients and that in 3/9 patients, MRI showed lesions sometimes associated with temporal lobe epilepsy (TLE).

In PNES+E patients, there were 8 cases of temporal lobe epilepsy, 2 cases of frontal lobe epilepsy, and 2 cases of generalised epilepsy. Also in this group, the following surgical interventions were utilised: temporal lobectomy (4 patients), and frontal lobectomy (1 patient) with an Engel's scale outcome of I in 4 and II in 1.

\subsection{Provocative techniques}

A provocative placebo technique was used to confirm a PNES diagnosis in 9 patients with an inconclusive diagnosis from vEEG monitoring. In 7 patients, the provocative test was positive for PNES, and in those cases, the patients experienced similar episodes to the previously recorded spontaneous episodes. However, a variable delay (of less than a minute) between saline administration and symptom onset was observed. The recorded bioelectric activity during the induced, as well as during spontaneous episodes, was completely normal, with visible muscle and movement artefacts. After a varying 30- to 60-second period after the episode started, we administered a second dose of saline after warning the patient that this drug would abort the crisis, which indeed occurred with a latency between 15 and $45 \mathrm{~s}$. One example of this technique is shown in Figure 2.

Provocative induction was positive for PNES in 7 patients. However in the other two patients we did not obtain any response.

\subsection{Diagnostic challenges}

Prolonged vEEG monitoring provides a definitive PNES diagnosis in nearly all cases. However, in some situations, a definitive PNES or epilepsy diagnosis can be difficult to obtain. Here, we describe a case in which the semiology and vEEG did not confirm that the episode was psychogenic in origin. Quantitative EEG (qEEG) had been used to assess the patient by both spectral and coherence methods while recording EEGs during basal conditions and episodes.

This patient, a 29 year old female, experienced seizure onset at 9 years old. The clinical symptomatology was described as an inability to emit and understand language, with feelings of sadness and fear. Moreover, the patient reported remaining conscious during the entire 


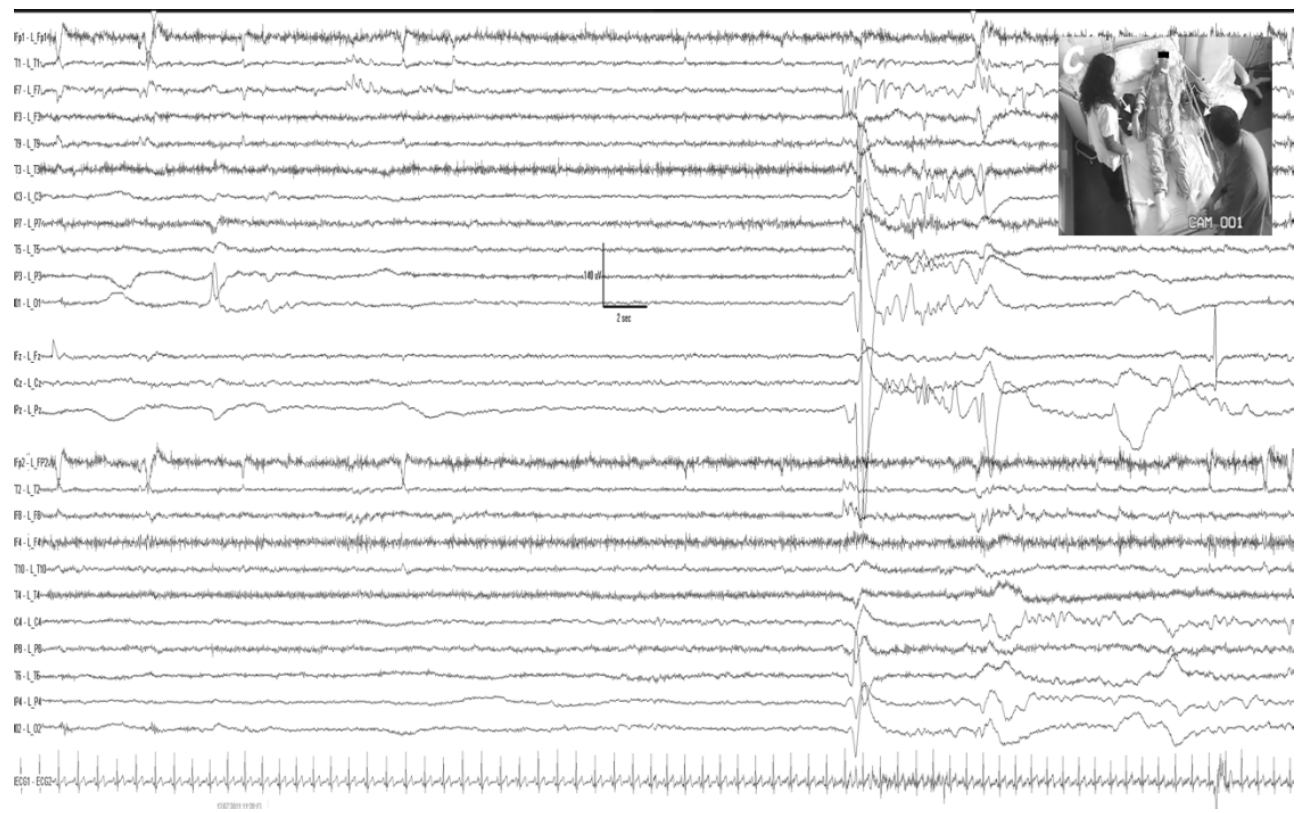

Figure 2. A typical recording during the provocative induction test. The image corresponds to $25 \mathrm{~s}$ after a 2 -ml saline injection. The patient (inset) experienced myoclonus of all four limbs. Two neurophysiologist (LV-Z and JP) were monitoring the patient's response. The EEG recording showed no pathological activity, except for movement artefacts.

episode and experienced no residual amnesia. The interictal EEG showed intense and very frequent irritative activity with a burst of epileptiform discharge in the left frontal area and a generalised spike-wave complex (Figure 3).

True seizures were recorded during the spike-wave discharges, which were accompanied by an altered state of consciousness, mild to severe difficulty to speak and a clear delay in response to different orders (Figure 4).

During the episodes, no clear evidence of any ictal pattern emerged. We conducted an induction test that proved positive, reproducing the previously described patient episodes (Figure 4).

In addition to this type of seizure (of which the patient did not complain), the patient complained of severe and multi-day seizures of language emission and difficulties in understanding. The brain activity recorded during these episodes did not show a clear ictal pattern. Nevertheless, the recorded bioelectrical activity needed to be classified as a seizure or another disorder. To assess these recordings, we analysed the band coherence $[C(f)]$ using to equation 1 and compared the basal and ictal activity using the $c(f)$ equation. We hypothesised that a true seizure most likely increases the local coherence for any scallop region (Figure 5). However, as shown in Figure 5, the local coherence was not significantly modified from basal activity during any of the recorded paroxysmal episodes. 


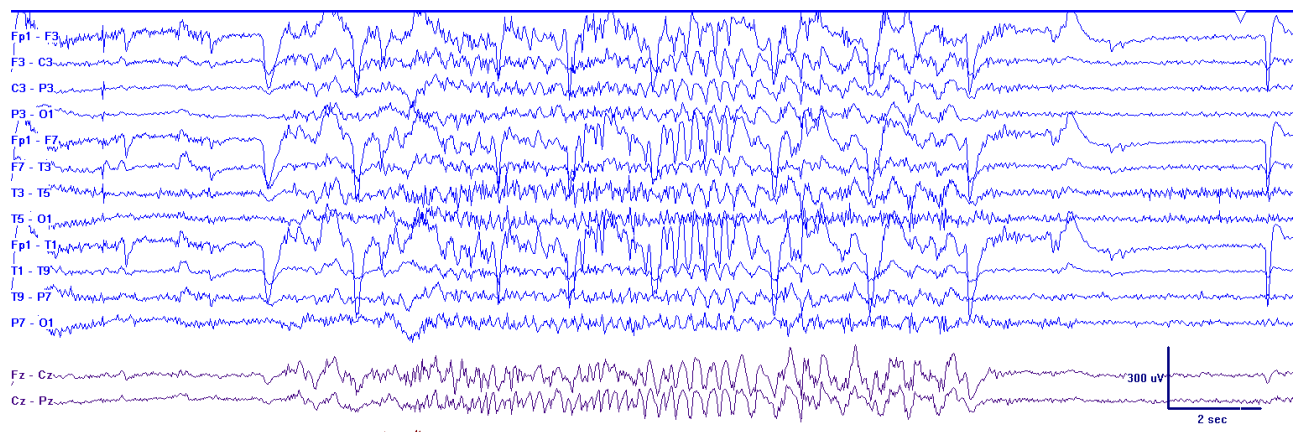

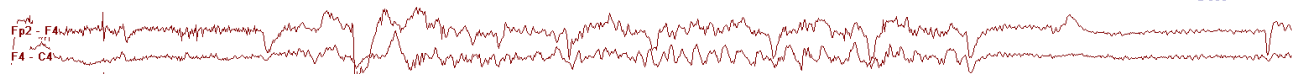
C4 - 4 a Fo 14- 16 .

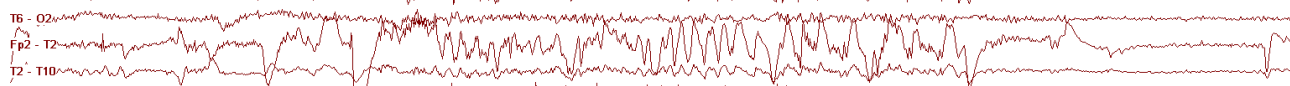

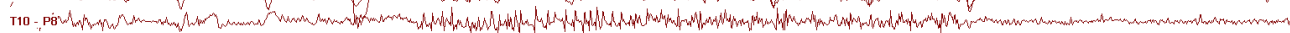

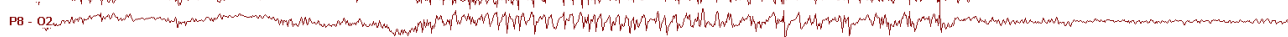

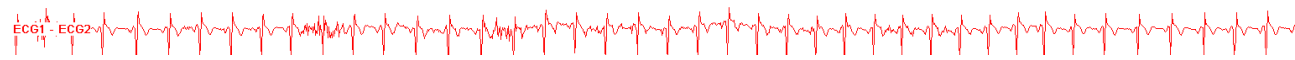

Figure 3. Wakeful interictal activity shows a burst of generalised spike-wave complexes.

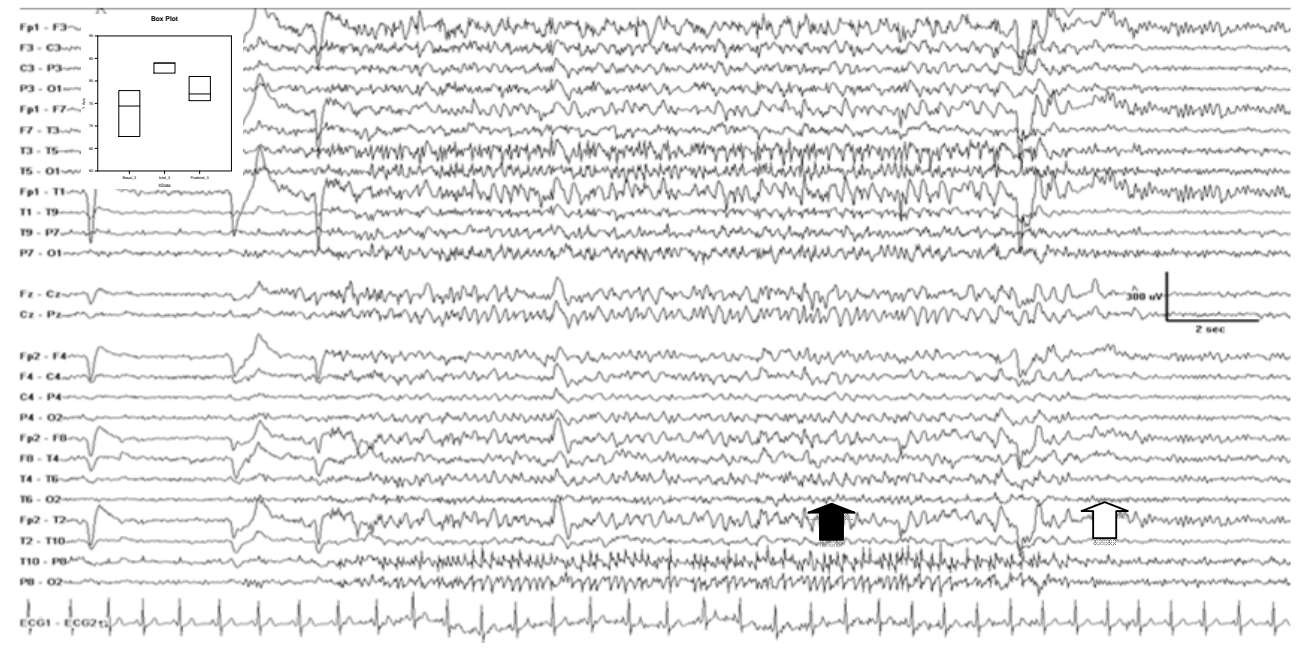

Figure 4. A burst of blunted spike-waves at $3 \mathrm{~Hz}$ shows a true alteration of consciousness. The patient was ordered to close her eyes (filled arrow), but the response was delayed by 6,4 s towards the end of the seizure. The HR (inset) increased from $72.8 \pm 1.8 \mathrm{bpm}$ before the burst to $83.7 \pm 0.7 \mathrm{bpm}$ during the episode $(p<0.05$, ANOVA test by ranks) and returned to $78.8 \pm 0.9 \mathrm{bpm}$ after the episode $(p<0.05$, ANOVA test). 


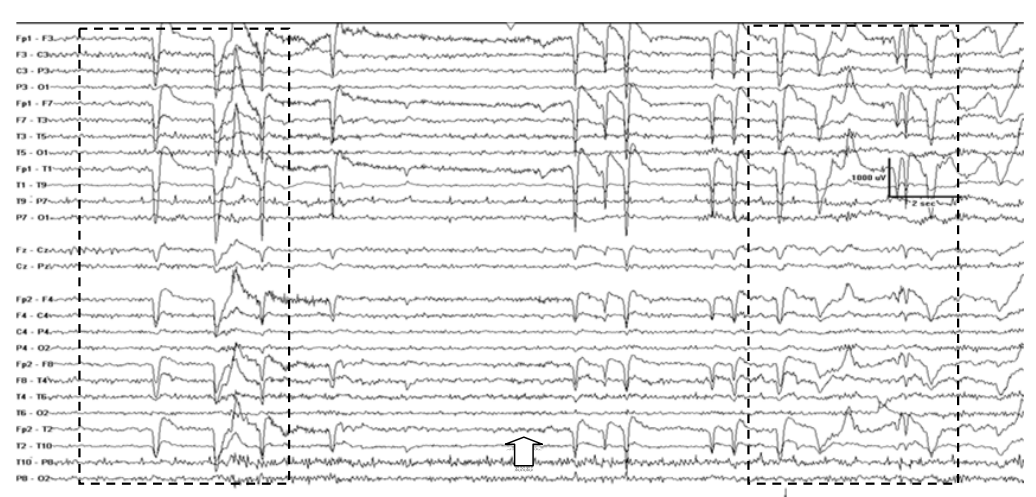

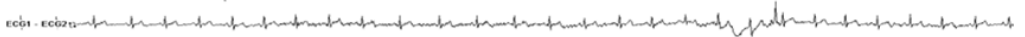
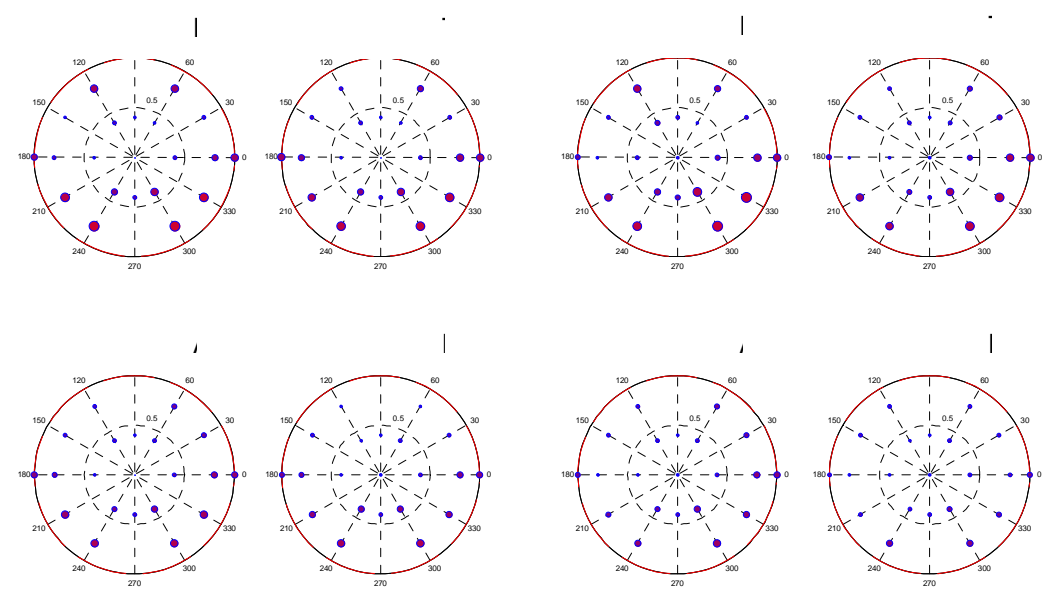

Figure 5. Quantitative EEG recordings assess the presence of epilepsy. A) Recording during a typical seizure. The empty arrow indicates when the patient pressed the patient-event button, which identifies the presence of a seizure. Dotted boxes indicate the basal (left) and ictal (right) periods selected for analysis. B) The EEG electrode schemes represent the 10-20 IS on the scalp. Local coherence was obtained using equation 2 for every electrode and every frequency band. Coherence is related to the diameter of each electrode, and no significant differences were observed between basal (left) and ictal activity (right).

Furthermore, after placebo injection, an episode was recorded that was similar to the spontaneously recorded episode, and this reinforced a PNES diagnosis.

\subsection{Psychiatric comorbidities and patient management}

The rate of psychiatric comorbidities in PNES patients was 50\%. Affective disorders were the most frequent psychiatric diagnosis (10/15), in particular, depression and anxiety disorders. Dissociative disorders were observed in 4 patients. Post-traumatic stress disorder was diagnosed in the remaining patient (Table 2). Interestingly, no differences were observed in the psychiatric comorbidities between the PNES+ E and PNES patients. 
Our preliminary data have confirmed reports in the literature detailing the higher disability observed in PNES patients compared with epilepsy patients. To provide proper patient management, we applied a protocol of patient management to all patients in our unit to provide the appropriate care to PNES and PNES+E patients (Table 4). We have observed that PNES patients showed good family integration, and both patients and families have adapted to the disorder, even in an overprotective way.

Neurologist refers patients to the Unit.

First Step. All patients are assessed by a:

Neurologist

or Neurosurgeon (if the patient has been referred for a neurosurgical evaluation)

Second Step. Ancillary tests and other specialists:

Scalp EEG

Single Photon Emission Computed Tomography (SPECT) with ${ }^{99} \mathrm{Tc}-\mathrm{HmPAO}$

MRI (1.5 T) with an epilepsy protocol

Psychiatrist

Neuropsychologist

Clinical decisions are determined in a regular multidisciplinary clinical meeting.

When PNES are detected, a more complex psychiatric assessment protocol is initiated

In patients with PNES, it is important to differentiate between PNES alone and PNES+E patients.

When patients suffer from PNES alone, a joint visit from a neurologist and psychiatrist are used to inform the patient and if possible, the closest family member about:

The psychogenic basis of the disorder, the diagnostic process and the likelihood of individualised psychoetiopathogenic mechanisms of the disorder.

The high disability associated with the disorder is also emphasised.

The need to treat the disorder with psychiatric and psychotherapy approaches.

The patient receives a complete clinical report to facilitate treatment continuation in his/her health care district.

The appropriate way to reduce neurological medications is supervised by a neurologist.

A close neurophysiological EEG survey is always recommended, which occurs during the progressive withdrawal from antiepileptic drugs.

Usually patients need to visit a neurologist and psychiatrist before completing care at his/her mental health centre.

When patients suffer from $\mathrm{PNES}+\mathrm{E}$, a joint visit from a neurologist and a psychiatrist is used to inform to the patient and if possible, the closest family member about:

The psychogenic basis of the disorder, the diagnostic process and the likelihood of individualised psychoetiopathogenic mechanisms of the disorder. The high disability associated with the disorder is also emphasised. The need to treat the disorder with psychiatric and psychotherapy approaches.

The patient is given a complete clinical report to facilitate mental health treatment in his/her health-care district. An individualised and thorough study of epilepsy is crucial to before deciding on surgery. In a small number of patients, epilepsy is detected during the $v E E G$, because of antiepileptic drug withdrawal; however, when AEDs are reintroduced, only the PNES are clinically significant.

Table 4. Protocol of Patient Management at the National Referral Centre for Refractory Epilepsy 


\section{Discussion}

\subsection{Characteristics of patients with non-epileptic seizures of psychogenic origin}

We have found that $4.8 \%$ of patients referred to our epilepsy centre for pre-surgical evaluation received a diagnosis of PNES. This percentage is lower than other published studies. However, PNES was the most frequent non-epileptic condition diagnosed in our epilepsy monitoring unit. Interestingly, in $90 \%$ of PNES+E patients, we discovered alterations in brain imaging studies, and also in more than half of the PNES-alone patients, we detected alterations in brain imaging studies. These findings have been previously described, and other researchers have found MRI changes in up to $60 \%$ of PNES+ E patients and up to $10 \%$ of PNES-alone patients [29]. If epileptiform activity is also considered as marker of brain abnormality, then the percentage of PNES patients in this study with evidence of physical or functional brain abnormalities was 55\%. This percentage, though lower than in previously reported studies, reinforces the theory that physical brain disease may play a role in PNES development and in other somatoform and dissociative disorders [30, 31, 32].

In this study, early diagnoses were complicated by concomitant epilepsy or epileptiform activity in 21 PNES patients; however, the semiology of the events helped differentiate PNES from epilepsy (closed eyes, non-rhythmic movements, awareness during the ictal phase and the ability of bystanders to modulate symptom intensity are more often observed in PNES). Nonetheless, no single observation provides a definitive PNES diagnosis, and no single semiological feature is shared by all PNES patients [33]. Moreover, eyewitness accounts of semiology may not be reliable in many cases. Usually, it is difficult for an experienced clinician to determine if an event is a true seizure or PNES, and generally, it is nearly impossible to rule out a diagnosis of epileptic seizures. The gold standard for ruling out epilepsy is vEEG telemetry that analyses typical seizures [34]. Observations of typical seizures combined with recorded brainwave activity lead to accurate diagnosis in up to $90 \%$ of cases [35]. In our study, $3,7 \%$ of patients did not receive a positive diagnosis because the bioelectric abnormalities or clinical manifestations typical of PNES were not observed. Thus, we could only conclude that the patient had no evidence of epilepsy, but it is possible that these patients might actually belong to the PNES group.

The diagnosis of PNES is difficult to obtain. In fact, the absence of epileptiform activity in scalp recordings during the event is necessary, and evidence of this can be extremely difficult to obtain, because a true partial seizure may have no significant changes in scalp recordings. In these cases, it is necessary to perform a more complex brain activity analysis to reach a definite and clear diagnosis. As misdiagnosis can lead to devastating consequences, all efforts should be made to determine the appropriate diagnosis, and in these cases, provocative techniques aid in providing a definitive diagnosis. We used these techniques in 9 patients to confirm a PNES diagnosis, and they were positive for PNES in 7 patients. The observed clinical manifestations were never associated with bioelectrical changes in the EEG recordings. The sensitivity to induction is unknown but estimated at 30\% [25]. The key factors in PNES diagnoses are confirming that the habitual episode was indeed induced and always obtaining a simultaneous vEEG. If the recorded episode is not the habitual type typically recognised by 
the patient and family, then a firm conclusion is unattainable, and most likely, the patient has different types of episodes. Another important issue is the awareness of the different types of seizures that can accompany a normal ictal EEG and which types cannot.

Another confounding factor in diagnosing PNES is that both epileptic seizures and PNES may occur concomitantly. Up to a $40 \%$ of our patients experienced PNES and epilepsy. Some authors estimated the prevalence of this comorbidity as ranging from $10 \%$ to $50 \%$ [36]. In 5 patients with PNES+E, we performed resective surgery. This determination was based on the results of vEEG, psychological and psychiatric assessments that suggested the decrease or disappearance of epileptic seizures could increase patient quality of life. The outcome of these patients is good; 4 patients showed Engel's grade I and the remaining patient an Engel's grade II.

\subsection{Psychiatric diagnosis}

When considering psychiatric disorders, some authors have found no differences in the prevalence of current axis I disorders in patients with recent-onset PNES+E [37]. Nevertheless, in most studies, a high prevalence of psychiatric comorbidities has been found, and up to $90 \%$ of PNES patients met the criteria for another psychiatric disorder, axis I or axis II, according to the DSM criteria. Although a significant degree of psychopathology has been documented, there is an absence of a unique character substrate. Despite numerous studies that have linked PNES to a high prevalence of comorbid psychiatric conditions, we found a low percentage $(40 \%)$ of the PNES patients exhibited these disorders. Furthermore, we did not observe differences in the psychiatric comorbid disorders of the PNES+E and PNES patient groups. However, we only detected dissociative disorder and post-traumatic stress disorder (PTSD) in the PNES-alone patients, but affective disorders were more common in the PNES+E group. Other studies have shown that approximately $60 \%$ of patients met the criteria for an affective episode [4, 5]. However, depressive symptoms are similar in PNES and epilepsy patients; thus, a negative affect could be the result of a chronic illness rather than uniquely related to PNES [38].

Other studies consider PNES as a heterogeneous entity, and to better understand it, different predisposing, precipitating and modulating factors must be considered. Patients with PNES usually present with a larger background of traumatic experiences than the general population [39], with values ranging from $84 \%[5,40]$ to approximately $40 \%$, in more recent studies $[4,38$, 41]. These studies have shown a higher incidence of adverse childhood experiences and life events [42]. Previous trauma correlated with a high rate of psychiatric comorbidity and with strong dissociative mechanisms [43]. Additionally, a consistent history of psychiatric treatment, suicide attempts, borderline personality disorder or a history of abuse have been documented [44].

Regarding dissociative disorders, different but high prevalence rates of comorbid dissociative disorders have been reported, which range from $37 \%$ to $80 \%$ of cases [4, 5]. Not only clinically diagnosed dissociative disorders but dissociative experiences appear to be more frequent in PNES patients, as measured with the Dissociative Experience scale (DES). Patients with epilepsy and PNES scored significantly higher on the DES than patients with epilepsy without PNES and non-epileptic individuals [45]. Nevertheless, these diagnoses have not been 
consistently correlated with significant differences in dissociative and conversion trait scores as determined with the Minnesota Multiphasic Personality Inventory (MMPI) [4].

Somatic syndromes, such as fibromyalgia, chronic fatigue syndrome, chronic pain syndrome or tension headaches, and irritable bowel syndrome, have occurred at a higher frequency in PNES patients than in other patients with epilepsy [46, 47]. Other medical conditions, such as cancer, orthopaedic problems, and multiple surgeries, were also more frequent in the PNES group than in the epilepsy group.

In PNES patients, this high prevalence of somatic syndromes could be related to a higher risk of manifesting psychic conflicts through somatic symptoms. In fact, PNES has been considered as a somatic symptom response to a wide range of negative events, including stress in adulthood [38].

\subsection{Psychological profile}

As we analysed the psychological evaluations from our study, we realised that the amount of information from the psychological profiles and psychopathological mechanisms warrants an extended discussion of both topics. Therefore, we will discuss the psychopathological mechanisms separately in the next section.

Most PNES patients met the criteria for a diagnosis of an axis II personality disorder (around $60 \%)[4,5]$, but patients with ES also had an increased prevalence of personality disorders. The prevalence of personality disorders in ES patients $34.3 \%$, which was significantly higher than healthy controls.

Nevertheless, some significant differences exist in the types of personality disorders diagnosed in the PNES and ES patients. In the ES group, the most common personality disorders were cluster $\mathrm{C}$ personality disorders (i.e., avoidant, dependent, and obsessive-compulsive disorders) $[48,49,50]$, and in PNES patients, cluster B personality disorders were more common (i.e., antisocial, borderline, histrionic and narcissistic disorders) [49, 50, 51, 52, 53,]. The presence of personality disorders is associated with a poor prognosis, diminished quality of life, and increased resource use in both PNES and ES patients $[3,4,48,51]$.

When personality traits have been assessed and specialised instruments used, a general, complex, and diverse psychological profile has been obtained, as evaluated with both neurotic and psychotic scales $[4,54]$. Thus, PNES personality profiles do not reveal a specific, unique syndrome [55].

The MMPI has been the most widely used inventory to classify personality traits. The higher personality assessment scores have been in somatisation and externalisation; these patients have a strong preference for a medical explanation for their symptoms and tend to project the burden of their symptoms to their environment instead of a possible psychological explanation for their disorder $[29,55]$. It is interesting to note that families of psychogenic seizure patients have also been found to be more prone to somatic problems and emotional distress than matched controls with epilepsy [56], hypochondriasis and conversion traits [4,57]. 
Dissociation scores have been widely studied and, on average, are higher in PNES patients but not significantly higher $[7,45,58,59]$. Dissociative trait scores were higher in patients with a reported trauma [7].

Additionally, an anxious, practical and perfectionist attitude with difficulties tolerating ambiguity and a strong need to control have also been reported [55]. Another study described increased shyness [7], which has been related to antisocial behaviour and a high tendency to internally control emotions [55].

PNES has been associated with an alexithymic pattern and a lack of psychological awareness of the causes and consequences of their psychological dysfunction [55]. Although alexithymia appears to be elevated in PNES, it has also been elevated in epilepsy patients [38]. PNES has been significantly correlated with symptoms of anxiety, autonomic hyperarousal, dissociation and defensive avoidance, which are all characteristic of traumatic experiences. Thus, alexithymia has been hypothesised as a deficit that results from physiological and cognitive dysregulation following post-traumatic stress disorder [60].

Another personality trait of PNES patients is difficulty with coping strategies. Elevated levels of perceived distress and a lack of coping strategies, such as a passive and/or avoidant attitude to resolve psychological problems in other ways [3, 61, 62], make it difficult to employ strategies that would normally be used to reduce the impact of a stressor [63]. Some effective minimal coping strategies, such as emotion-focused coping strategies, are more frequently used than effective coping strategies, such as task-focused strategies [60]. These features lead to difficulties in emotional experiences to daily life situations, and diminished positive emotional behaviour has also been reported [64].

Two emotion dysregulation profiles have been described [65], a high level of emotion dysregulation associated with severe psychiatric symptomatology and impaired quality of life and low emotion dysregulation that is characterised by emotional unawareness or avoidance.

Some common personality traits as well as some clinical similarities have been documented between PNES and borderline personality disorder patients. Higher prevalence rates of sexual trauma, posttraumatic stress disorder, dissociative disorders, somatoform disorders, depressive disorders, anger problems, suicide attempts, emotional instability and hostile coping styles have been reported in both conditions $[49,50,52,66]$.

Some similarities in personality traits have also been found between PNES and patients with functional somatic symptoms disorders [55].

Although the interpersonal relationships of PNES patients in clinical practice appear to be deeply affected, their social functioning scores remain within normal limits [4]. These patients make instrumental use of the PNES, which may contribute to the perception of being well-adapted in their relationships. Patients with higher emotional dysfunction and higher abnormal personality traits have a lower quality of life [47]. 


\subsection{Etiopathogenic models of PNES}

The final symptomatic expression of PNES remains unclear. Some etiopathogenic theories that comprehensively address many factors have been previously reported and have been hypothesised to explain psychogenic seizures.

Bodde y cols [55] considered factors that predispose patients to psychosomatic symptoms and increase PNES vulnerability.

Sexual abuse, other traumatic experiences, organic vulnerability (such as head trauma) and personality factors (emotional profile or neuropsychological functioning) increase PNES vulnerability. Stressful childhood events, including parental divorce and physical abuse [67], other childhood trauma and family dysfunction [68] also increase PNES vulnerability.

The observed personality traits have a tendency towards somatisation or dissociative experiences or reaction with somatic symptoms of psychological distress [7]. Alexithymia, cognitive inflexibility and hypervigilance have also been considered as PNES vulnerability factors [69].

Factors that shape patient perceptions could explain the presence of seizures and not other functional disorders, such as past epilepsy or having a close friend or relative with epileptic seizures. When examined, personally witnessing a seizure prior to their own attack occurs significantly more often in patients with PNES than in patients with epileptic seizures [67, 70].

Triggering factors, such as some psychological mechanisms or psychosocial events, might provoke seizure onset at specific moments. PNES patients report more events than epilepsy patients or patients with motor conversion disorders [67].

Thus, prolongation factors could explain the persistence of PNES over time.

The modulating factors, e.g., personality [3], patient coping style and secondary gain aspects, could also contribute. There are some criticisms of secondary gain, as this benefit can be observed in almost any illness [67].

\subsection{PNES subtypes}

In general psychopathology, somatisation, alexithymia and difficulties with most aspects of emotional regulation could be the most important factors in the etiopathogenesis of PNES [71].

Considering all the etiopathogenic factors, some studies have proposed different etiopathogenic subgroups.

Reuber and House [2] classified PNES into 3 groups based on the most prominent psychiatric comorbidity profiles: an anxiety-depressive group with depressive or anxiety symptoms, including panic and post-traumatic stress disorder (PTSD), a somatisation and abnormal illness group and a borderline personality group.

Bodde et al. [55] proposed 4 etiopathogenic groups: a psychotrauma subgroup, a high vulnerability somatisation subgroup (approximately $1 / 5$ of patients), a sensitive personality subgroup (less than $1 / 5$ of the patients) and a high vulnerability somatisation, low cognitive level subgroup with daily life stress. 
Other authors proposed a more simplified, two-subgroup etiopathogenic classification scheme: a posttraumatic PNES group, characterised by psychogenic attacks that develop in response to acute or chronic traumatic experience exposure, and developmental PNES group, characterised by difficulties in coping with tasks and milestones on the individual's psychosocial development continuum [71].

The importance of diagnosis presentation

The first step towards symptom improvement is presenting the diagnosis to the patient and when appropriate, to his or her family. Providing patients with a PNES diagnosis, appears to reduce PNES frequency in the months following diagnosis in at least one third of patients [69, $72,73,74,75,76]$.

A marked reduction in health care demand after PNES diagnosis has also been established by prospective follow-up studies [10, 69, 77]. However, long-term studies examining the decrease in PNES frequency shortly after diagnosis has not been maintained longitudinally when a diagnosis is the main and sole "intervention" [3, 58].

Effectively communicating the PNES diagnosis in an understandable and acceptable way to the patient and family is critical and is considered the first therapeutic step.

The process of explaining to the patients that their disease may be psychiatric instead of neurological must be cautiously and progressively handled [16]. Patients and family must be engaged in a treatment plan very different from the previous plan.

A significant patient and family resistance to a new and non-neurologic diagnosis requires the implementation of coordinated strategies by a neurologist and a psychiatrist to manage the best outcome for these patients. When a diagnosis is given to patients and families, some of patients have a sense of relief to know that the events are not epileptic and that they will be helped in identifying sources of stress and other emotional problems responsible for triggering their events [75]. However, most patients react negatively to the diagnosis of PNES. Frequently, they feel that doctors are communicating that the symptoms are not real but invented.

Many factors may contribute to this negative, even hostile, attitude towards a psychogenic basis of their crisis $[46,52]$. Some personality trait factors, such as somatisation and externalisation traits, make diagnosis acceptance difficult. Patients and families show a tendency to seek medical responsibility for these symptoms and might be very reluctant to be referred for psychological or psychiatric treatment.

An indirect benefit obtained through this behavioural pattern may also help explain their resistance to change [4].

Another factor related to the initially hostile attitude of the patients is the risk of stigma, which is inherent to psychiatric disorders. Patients fear being viewed as malingerers or attention seekers [74], and also the not infrequent stigmatisation of the doctor, who only considers neurologic diseases real diseases, may transmit this bias that a psychogenic crisis is not a real disease to patients. These stigmatising views can lead patients to believe that they do not need attentive specialised and technical care but a psychiatric clinic for insane individuals. 
All these difficulties in the diagnosis and treatment of PNES patients must be considered when deliberating over the most effective strategy to provide information about a PNES diagnosis to patients previously considered neurologic patients.

A good therapeutic relationship between the neurologist and patient is crucial. One or several clinical interviews involving a neurologist, psychiatrist and patient that provide a multidisciplinary presentation of the diagnosis and treatment plan are highly recommended.

When presenting a PNES diagnosis, it is recommended to explain to patient and family the lack of ictal discharges during vEEG, the psychogenic nature of the attacks as a result of difficulties managing stressful or life situations, the acknowledgement that the attacks are real and out of the patient's control and the need for psychotherapeutic and/or psychiatric treatment to managing stressful situations and psychiatric comorbidities. Unless patients and families understand and accept the diagnosis, they typically will not comply with recommendations and will not follow-up with a psychiatrist.

A neurologist will continue to provide care, monitoring the patient outcome, and progressively decreasing antiepileptic drug doses when appropriate.

If patients present with both PNES and epilepsy and antiepileptic drugs must be maintained, patients will need to be informed and must understand both the neurologic and psychiatric treatments. However, some controversy exists about the discontinuation of antiepileptic drugs in PNES patients without epilepsy. Antiepileptic drugs could provide therapeutic benefits on mood and impulsivity and for headache or pain prophylaxis. On the contrary, toxicity, teratogenicity and medication expense need to be considered [78].

\subsection{Treatment}

The treatment plan must be individually adjusted to each patient, depending on the psychogenic factors considered to underlie the psychopathology [7, 79, 80].

For example, if difficulties in emotional reactions occur, some strategies, such as monitoring symptom triggers, re-interpreting physical sensations and increasing relaxation, could be effective in PNES patients [64].

\subsection{Psychotherapy}

Most psychotherapy techniques, such as psychodynamic interpersonal psychotherapy, group psychodynamic psychotherapy and group psychoeducation, have been evaluated in uncontrolled trials. These interventions all seem promising but require further investigation in larger scale samples and/or more rigorous methodology.

\subsection{Cognitive-Behavioural Therapy (CBT)}

CBT is based on the conceptualisation of PNES as dissociative responses to arousal when a patient is confronted with stimuli or circumstances that the patient tends to avoid, consciously or not. 
Patients with PNES tend to display significantly distorted somatic beliefs and develop dysfunctional, repetitive illness behaviour patterns with associated depressive affect as well as a sudden and time-limited disturbance in controlling cognitive, emotional, and/or behavioural functions $[70,79]$. CBT is intended to modify distorted beliefs and change the perception of the limitations associated with PNES.

This therapy may be useful several symptom patterns: (a) acute anxiety/panic, (b) impaired affect regulation and interpersonal skills, (c) somatisation/conversion, (d) depression, (e) PTSD, and (f) reinforced behavioural patterns [80]. These classifications were based on the most effective psychotherapeutic interventions for each patient group.

CBT is the only psychotherapeutic PNES intervention that has been studied in a randomised, controlled pilot trial and is therefore the psychotherapeutic treatment with the highest level of efficacious evidence (Class III) in this population. Goldstein et al. [81] reported that in an open-label trial for patients with dissociative seizure, a 12-session CBT intervention was significantly more effective than standard medical care (SMC) for reducing seizure frequency in PNES patients. Psychotherapy focused on the following factors: engagement in treatment, reinforcement of independence, distraction, relaxation, refocusing techniques at the earliest signs of an event, graded exposure to avoided situations, cognitive restructuring, and relapse prevention. A tendency for this benefit to persist was maintained at the 6-month follow-up. There was also an overall improvement in self-rated social functioning of the CBT group compared with SMC.

Moreover, an uncontrolled CBT study where therapy was focused on addressing cognitive distortions and promoting behavioural changes has been published [82]. Some specific objectives of the psychotherapeutic sessions included the study of the individual's context, identification of moods, situations, and thoughts, training in healthy communication and support seeking, understanding central nervous system medications and seizures, conducting a functional behavioural analysis, developing relaxation techniques, examining external stressors and internal triggers, and preparing for life after completing the time-limited intervention. Patients reduced the number of PNES and improved quality of life, family functioning, and psychosocial functioning.

In summary, the data on CBT efficacy for PNES treatment are sparse but promising.

\subsection{Group therapy}

To date, several studies have reported the use of group therapy for PNES patients.

Zaroff et al. [83] evaluated the effectiveness of group psychotherapy based on psychodynamic theories and a psychoeducational session structure. All patients included in this open-label trial participated in a one-hour weekly group psychotherapy session for a total of 10 weeks. In each session, the following relevant PNES topics were discussed: PNES, anger, trauma and abuse, depression and anxiety, somatisation tendencies, quality of life, paths toward health, stress coping techniques and topic review. At the conclusion of the 10-week program, group psychotherapy continued in a less structured and more supportive format without specific 
session topics. The substantial percentage of individuals whose seizures remitted following diagnosis supports the hypothesis that education about the disorder is an effective treatment.

The results of a six-month psychotherapy group, with an open, uncontrolled design [84], have been published. Over a total of 24 sessions, the discussion of feelings related to past or present events relevant to PNES was encouraged. A decrease in seizure frequency was reported in six of the nine PNES subjects (67\%).

In another pilot study with a psychodynamic focus and psychoeducational structure, selfrelaxation with hypnosis was also used [85]. Dissociation was considered a defence mechanism that splits traumatic memories from consciousness because they are inconsistent with the patient's self-concept. The goal of therapy was to facilitate the patient's awareness of these patterns and to thus allow change. The development of assertive coping strategies instead of passive avoidant behaviour was emphasised. The study reported an overall decrease in seizure frequency and a significant improvement in different psychometric assessments.

Recently, another uncontrolled study with group psychotherapy has been published [86]. Psychoeducation and behavioural and psychoanalytic techniques were utilised. Nine patients completed 12 weeks of psychotherapy. In this therapy, families gathering four times for $1 \mathrm{~h}$ during the study provided a different treatment element. Families were not included in the therapeutic process and met just before the group sessions. Families were encouraged to ask questions and talk about seizures, and behavioural management strategies were advised. A sustainable decrease in seizure frequency, which lasted from the beginning of the therapy until the $12^{\text {th }}$ month of follow-up, was observed. All patients showed a $>50 \%$ reduction in seizure frequency.

\subsection{Paradoxical intention therapy}

This technique has been used in PNES and conversion disorder patients. In a randomised trial of PNES patients, Ataoglu et al. [87] tested inpatient paradoxical intention (PI) therapy versus oral outpatient benzodiazepine. PI therapy consisted of encouraging patients to intentionally engage in their unwanted conversion symptoms. This study did not focus on crisis frequency but on conversion symptoms. Both groups recorded significantly decreased anxiety scores by the end of treatment.

\subsection{Hypnosis}

Given the theoretical importance of dissociation in PNES aetiology, hypnosis would appear to offer a useful intervention for this patient population [72]. The effectiveness of hypnosis was evaluated in a prospective study [88] where 49 patients were randomly assigned to either a hypnosis-based 10-week session treatment for conversion disorder, motor type, or a wait list control group. Only two patients in this conversion disorder study had PNES. A significant improvement in the Motor Conversion Symptoms scale (VRMC) for the treatment group was observed.

Other studies evaluated dissociation and hypnotisability in PNES patients and compared them with a nonclinical control group or epilepsy patients. In one study, PNES patients had higher 
levels of dissociation and hypnotisability as measured by the Dissociative Experience Scale (DES) [61]. Hypnotisability was also significantly higher for the PNES group compared with the control group, as other authors have previously reported [89].

\subsection{Pharmacological treatment}

To date, the lack of a consistent neurobiological model explaining PNES physiopathology makes it considerably difficult to identify a specific and effective pharmacological treatment. Owing to a lack of large, controlled trials evaluating the efficacy of different treatment modalities, guidelines on how to treat this complex health problem do not exist [16, 79].

Nonetheless, under the premise that some of the factors that seem to be involved in PNES etiopathogenesis, such as depressive mood and anxiety, are associated with serotonergic neurotransmission alterations, selective serotonin reuptake inhibitors (SSRIs) have been investigated as potentially useful drugs. In addition to their established efficacy for treating depression and anxiety [90, 91], SSRIs have shown promise in trials for conversion or somatoform disorders [92] and some personality disorders [93]. These disorders are frequently occurring comorbidities in PNES patients, which make SSRIs particularly attractive as a potential treatment.

LaFrance et al. conducted a randomised, double-blind, placebo-controlled clinical trial (which meets the criteria for Class II evidence) evaluating the efficacy of flexible-dose sertraline over 12 weeks at reducing PNES frequency and improving other symptom severity and psychosocial measures [94]. Patients were allowed to participate even with previous antidepressant use, except for monoamine oxidase inhibitors or sertraline at a $100 \mathrm{mg} /$ day or higher dose, to maintain a constant dose of the concurrent antidepressants for the study duration. The sertraline group experienced a $45 \%$ decline in biweekly seizure rates over the 12 -week course of the intervention from 22.24 to 12.18 (ratio, $0.55 ; 95 \% \mathrm{CI}, 0.32-0.93 ; \mathrm{p}=0.03$ ), while the control group showed an $8 \%$ increase from 13.38 to 14.38 (ratio, 1.08; 95\% CI, 0.65-1.77; p = 0.78). However, the limited sample size (33 patients were included in the final analysis) implied this study was underpowered and unable to detect statistically significant differences between groups (RR, $0.51 ; 95 \% \mathrm{CI}, 0.25-1.05 ; \mathrm{p}=0.29)$. There were no differences in secondary outcome measure changes between the groups (a series of scales assessing different psychiatric symptoms, functionality and quality of life-related measures). The evaluation of SSRIs in larger, randomised, controlled trials is therefore necessary to establish solid treatment guidelines.

Venlafaxine, a noradrenalin-serotonin reuptake inhibitor (NSRI), has also been evaluated as a potential psychopharmacological PNES treatment. An open-label, prospective, uncontrolled study evaluated the efficacy of flexible-dose venlafaxine on seizure frequency reduction and anxiety and depression disorder severity improvement [95]. All enrolled subjects had vEEGconfirmed PNES but also met the DSM-IV criteria for a unipolar depressive disorder and/or anxiety disorder. The 19 subjects who completed the 5-month follow-up experienced a statistically significant reduction in all symptom scales and monthly event frequency at the five-month assessment compared with the initial assessment; however, no differences were detected in the patient subgroup with more than ten events in the 15-day baseline pre-inclusion 
assessment period. The particular comorbidities of the patients included in this study prevent the extrapolation of the results to the broader PNES population, but the combined prevalence of depressive and anxiety disorders among PNES patients that may reach up to two thirds of PNES patients should not be ignored [4]. An additional caution when interpreting these results is the lack of a placebo-arm, especially if we consider the documented initial decrease in seizure frequency consistently observed during the first months after PNES diagnosis $[16,73,75,76]$. This factor could account for some of the event frequency reductions described in this study.

Clinicians have often tried other pharmacological PNES treatments based on current knowledge of PNES-related disorders. As we have previously described, patients suffering from PNES share many underlying psychopathological characteristics with other conversion and somatoform disorders. These comorbidities may lead to the hypothesis that treatments demonstrating efficacy for these other disorders might also provide some benefit in PNES.

Evidence-based treatments for other conversion disorders have been documented in uncontrolled trials. A retrospective study on patients with psychogenic paralysis showed that repetitive Transcranial Magnetic Stimulation (rTMS) over the motor cortex contralateral to the corresponding paralysis achieved improvement in 62 of 70 patients $(89 \%)$, with total recovery observed in 53 patients (76\%) [96].

In an open-label, prospective study conducted on 23 patients diagnosed with chronic psychogenic movement disorder (PMD), antidepressant medications (paroxetine, citalopram and venlafaxine) showed a reduction and even remission of psychogenic movements in the subgroup of patients in which the movements were not accompanied by other somatoform disorders, such as hypochondriasis or somatisation disorders [92]. Various classes of antidepressants have also demonstrated a reduction in medically unexplained symptoms, including headache, fibromyalgia, functional gastrointestinal syndromes, idiopathic pain, tinnitus, and chronic fatigue [97].

In summary, no strong evidence exists to date that establishes the efficacy of any particular medication for the treatment of PNES. Despite this fact, preliminary studies suggest that sertraline and venlafaxine could be beneficial therapeutics. The data investigating treatments for PNES-related disorders also support this hypothesis

\section{Conclusions}

PNES is one of the most frustrating clinical pathologies. Diagnosis is sometimes difficult and can take several years to reach a definitive PNES diagnosis. Moreover, treatment can be even more difficult. However, PNES is a severely debilitating illness for the patient, family and society; thus, we must continue to identify and improve patient quality-of-life. Nevertheless, a significant percentage of patients referred to epilepsy surgery units present with PNES, where the necessary assessments, such as VEEG, can provide a correct diagnosis; therefore, the actual magnitude of PNES diagnoses may be larger than currently detectable. 
Hence, when assessing patients with epilepsy, the PNES pathology should be kept in mind and patients should be sent to a specialised unit, even under the minimal suspicion of PNES, to provide a correct diagnosis in a timely manner. These steps should minimise medication side-effects and consumption of health care resources and offer the patient the most efficacious treatment.

\section{Acknowledgements}

This work was supported by a grant from the Plan Nacional de Investigación Científica, Desarrollo e Innovación Tecnológica (I+D+I), Instituto de Salud Carlos III, Subdirección General de Evaluación y Fomento de la Investigación PI12/02839.

\section{Author details}

Lorena Vega-Zelaya', Marta Alvarez², Elena Ezquiaga², Jaime Nogeiras², María Toledo², Rafael G. Sola ${ }^{4}$ and Jesús Pastor ${ }^{1 *}$

*Address all correspondence to: jesus.pastor@salud.madrid.org

1 Clinical Neurophysiology, National Referral Centre for Refractory Epilepsy, Hospital La Princesa, Madrid, Spain

2 Psychiatry, National Referral Centre for Refractory Epilepsy, Hospital La Princesa, Madrid, Spain

3 Neurology, National Referral Centre for Refractory Epilepsy, Hospital La Princesa, Madrid, Spain

4 Neurosurgery, National Referral Centre for Refractory Epilepsy, Hospital La Princesa, Madrid, Spain

\section{References}

[1] Bowman ES, Coons PM. The differential diagnosis of epilepsy, pseudoseizures, dissociative identity disorder, and dissociative disorder not otherwise specified. Bull Menninger Clin. 2000;64(2) 164-80.

[2] Reuber M, House AO. Treating patients with psychogenic non-epileptic seizures. Curr Opin Neurol. 2002;15(2) 207-11. 
[3] Bodde NM, Brooks JL, Baker GA, Boon PA, Hendriksen JG, Mulder OG, Aldenkamp AP. Psychogenic non-epileptic seizures - definition, treatment and prognostic issues: a critical review. Seizure 2009;18(8) 543-53.

[4] Bailles, E, Pintor L, Torres X, Fernández-Egea E, de Pablo J, Arroyo S. Psychiatric disease in patients with psychogenic non-epileptic seizures referred from an epilepsy unit in a general hospital. Actas Esp Psiquiatr 2004;32(2): 76-81.

[5] Bowman ES, Markand ON. Psychodynamics and psychiatric diagnoses of pseudoseizure subjects. Am J Psychiatry. 1996;153(1) 57-63.

[6] Ribai P, Tugendhaft P, Legros B. Usefulness of prolonged Video-EEG monitoring and provocative procedure with saline injection for the diagnosis of non epileptic seizures of psychogenic origin. J. Neurol 2006;253(3) 328-32.

[7] Bodde NM, van der Kruijs SJ, Ijff DM, Lazeron RH, Vonck KE, Boon PA, Aldenkamp AP. Subgroup classification in patients with psychogenic non-epileptic seizures. Epilepsy Behav. 2013;26(3) 279-89.

[8] Reuber M, Elger CE. Psychogenic nonepileptic seizures: review and update. Epilepsy Behav 2003;4(3) 205-16.

[9] Lobello K, Morgenlander JC, Radtke RA, Bushnell CD. Video/EEG monitoring in the evaluation of paroxysmal behavioural events: duration, effectiveness, and limitations. Epilepsy Behav 2006;8(1) 261-6.

[10] Razvi S, Mulhern S, Duncan R. Newly diagnosed psychogenic nonepileptic seizures: health care demand prior to and following diagnosis at a first seizure clinic. Epilepsy Behav. 2012;23(1) 7-9.

[11] Reuber M. The etiology of psychogenic non-epileptic seizures: toward a biopsychosocial model. Neurol Clin. 2009;27(4) 909-24.

[12] O'Sullivan SS, Spillane JE, McMahon EM, Sweeney BJ, Galvin RJ, McNamara B, Cassidy EM. Clinical characteristics and outcome of patients diagnosed with psychogenic nonepileptic seizures: a 5-year review. Epilepsy Behav. 2007;11(1) 77-84.

[13] Reuber M, Baker GA, Gill R, Smith DF, Chadwick DW. Failure to recognize psychogenic nonepileptic seizures may cause death. Neurology. 2004;62(5) 834-5.

[14] Szaflarski JP, Szaflarski M, Hughes C, Ficker DM, Cahill WT, Privitera MD. Psychopathology and quality of life: psychogenic non-epileptic seizures versus epilepsy. Med Sci Monit. 2003;9(4) CR113-8.

[15] Testa SM, Schefft BK, Szaflarski JP, Yeh HS, Privitera MD. Mood, personality, and health-related quality of life in epileptic and psychogenic seizure disorders. Epilepsia. 2007;48(5) 973-82. 
[16] Baslet G. Psychogenic nonepileptic seizures: a treatment review. What have we learned since the beginning of the millennium? Neuropsychiatr Dis Treat. 2012;8 $585-98$

[17] Breier JI, Fuchs KL, Brookshire BL, Wheless J, Thomas AB, Constantinou J, Willmore LJ. Quality of life perception in patients with intractable epilepsy or pseudoseizures. Arch Neurol. 1998;55(5) 660-5.

[18] Dixit R, Popescu A, Bagić A, Ghearing G, Hendrickson R. Medical comorbidities in patients with psychogenic nonepileptic spells (PNES) referred for video-EEG monitoring. Epilepsy Behav. 2013;28(2) 137-40.

[19] Noe KH, Grade M, Stonnington CM, Driver-Dunckley E, Locke DE. Confirming psychogenic nonepileptic seizures with video-EEG: sex matters. Epilepsy Behav. 2012;23(3) 220-3.

[20] Behrouz R, Heriaud L, Benbadis SR. Late-onset psychogenic nonepileptic seizures. Epilepsy Behav. 2006;8(3) 649-50.

[21] Hermann BP. Neuropsychological assessment in the diagnosis of non-epileptic seizures. In: Rowan AJ, Gates JR, (ed) Non-epileptic Seizures. Stoneham, MA: Butterworth-Heinemann; 1993. p. 221-32.

[22] Pastor J, Hernando-Requejo V, Domínguez-Gadea L, De Llano I, Meilán-Paz ML, Martínez-Chacón JL, et al. Impacto de la experiencia sobre los resultados quirúrgicos en la epilepsia del lóbulo temporal. Rev Neurol 2005;41(12) 709-16.

[23] Sola RG, Hernando-Requejo V, Pastor L, García-Navarrete E, De Felipe J, Alijarde MT, Sánchez A, Domínguez-Gadea L, Martín-Plasencia P, Maestú F, Ramón-Cajal S, Pulido-Rivas P. Epilepsia farmacorresistente del lóbulo temporal. Exploración con electrodos del foramen oval y resultados quirúrgicos. Rev Neurol. 2005;41(1) 4-16.

[24] Commission on Classification and Terminology of the International League Against Epilepsy. Proposal for Revised Classification of Epilepsies and Epileptic Syndromes. Epilepsia. 1989;30(4) 389-99.

[25] Benbadis SR. Provocative techniques should be used for the diagnosis of psychogenic nonepileptic seizures. Epilepsy Behav 2009;15(2) 106-9.

[26] Gallego I, Ezquiaga E, Betancor D, Sola RG, Pastor J. Crisis no epilépticas de origen psicógeno en una unidad de cirugía de la epilepsia. Rev Neurol 2011;52(8) 449-56.

[27] Shaw JC. An introduction to the coherence function and its use in EEG signal analysis. J Med Engineering \& Technology. 1981;5(6) 279-288.

[28] Ortega GJ, Menendez de la Prida L, Sola RG, Pastor J. Synchronization clusters of interictal activity in the lateral temporal cortex of epileptic patients: intracranial analysis. Epilepsia 2008;49(2) 269-280. 
[29] Reuber M, Fernández G, Helmstaedter C, Qurishi A, Elger CE. Evidence of brain abnormality in patients with psychogenic nonepileptic seizures. Epilepsy \& Behavior 2002;3(3) 249-254.

[30] Devinsky O, Mesad S, Alper K. Nondominant hemisphere lesions and conversion nonepileptic seizures. J Neuropsychiatry Clin Neurosci 2001;13(3) 367-73.

[31] Glosser G, Roberts D, Glosser DS. Nonepileptic seizures after resective epilepsy surgery. Epilepsia 1999;40(12) 1750-4.

[32] Labate A, Cerasa A, Mula M, Mumoli L, Gioia MC, Aguglia U, Quattrone A, Gambardella A. Neuroanatomic correlates of psychogenic nonepileptic seizures: a cortical thickness and VBM study. Epilepsia. 2012;53(2) 377-85.

[33] Leis AA, Ross MA, Summers AK. Psychogenic seizures: ictal characteristics and diagnostic pitfalls. Neurology 1992;42(1) 95-9.

[34] Alsaadi TM, Thieman C, Shatzel A, Farias S. Video-EEG telemetry can be a crucial tool for neurologists experienced in epilepsy when diagnosing seizure disorders. Seizure 2004;13(1) 32-4.

[35] LaFrance WC Jr. Psychogenic nonepileptic seizures. Curr Opin Neurol. 2008;21(2) 195-201.

[36] Turner K, Piazzini A, Chiesa V, Barbieri V, Vignoli A, Gardella E, Tisi G, Scarone S, Canevini MP, Gambin O. Patients with epilepsy and patients with psychogenic nonepileptic seizures: Video-EEG, clinical and neuropsychological evaluation. Seizure 2011;20(9) 706-710.

[37] Binzer M, Stone J, Sharpe M. Recent onset pseudoseizures--clues to aetiology. Seizure. 2004;13(3) 146-55.

[38] Tojek TM, Lumley M, Barkley G, Mahr G, Thomas A. Stress and other psicosocial characteristics of patients with psychogenic nonepileptic seizures. Psychosomatics. 2000;41(3) 221-6.

[39] Gumnit RJ, Gates JR. Psychogenic seizures. Epilepsia. 1986;27(2) S124-9.

[40] Arnold LM, Privitera MD. Psychopathology and trauma in epileptic and psychogenic seizure patients. Psychosomatics 1996;37(5) 438-43.

[41] Myers L, Perrine K, Lancman M, Fleming M, Lancman M. Psychological trauma in patients with psychogenic nonepileptic seizures: trauma characteristics and those who develop PTSD. Epilepsy Behav. 2013;28(1) 121-6.

[42] Stone J, Binzer M, Sharpe M. Illness beliefs and locus of control: a comparison of patients with pseudoseizures and epilepsy. J Psychosom Res. 2004;57(6) 541-7.

[43] Hingray C, Maillard L, Hubsch C, Vignal JP, Bourgognon F, Laprevote V, Lerond J, Vespignani H, Schwan R. Psychogenic nonepileptic seizures: characterization of two 
distinct patient profiles on the basis of trauma history. Epilepsy Behav. 2011;22(3) 532-6.

[44] Stewart RS, Lovitt R, Stewart RM. Are hysterical seizures more than hysteria? A research diagnostic criteria, DMS-III, and psychometric analysis. Am J Psychiatry. 1982;139(7) 926-9.

[45] Ito M, Adachi N, Okazaki M, Kato M, Onuma T. Evaluation of dissociative experiences and the clinical utility of the Dissociative Experience Scale in patients with coexisting epilepsy and psychogenic nonepileptic seizures. Epilepsy Behav. 2009;16(3) 491-4.

[46] Mökleby K, Blomhoff S, Malt UF, Dahlström A, Tauböll E, Gjerstad L. Psychiatric comorbidity and hostility in patients with psychogenic nonepileptic seizures compared with somatoform disorders and healthy controls. Epilepsia. 2002;43(2) 193-8.

[47] Myers L, Lancman M, Laban-Grant O, Matzner B, Lancman M. Psychogenic non-epileptic seizures: predisposing factors to diminished quality of life. Epilepsy Behav. 2012;25(3) 358-62.

[48] Devinsky O. Psychiatric comorbidity in patients with epilepsy: implications for diagnosis and treatment. Epilepsy Behav. 2003;4(4) S2-10.

[49] Harden CL, Jovine L, Burgut FT, Carey BT, Nikolov BG, Ferrando SJ. A comparison of personality disorder characteristics of patients with nonepileptic psychogenic pseudoseizures with those of patients with epilepsy. Epilepsy Behav. 2009;14(3) 481-3.

[50] Direk N, Kulaksizoglu IB, Alpay K, Gurses C. Using personality disorders to distinguish between patients with psychogenic nonepileptic seizures and those with epileptic seizures. Epilepsy Behav. 2012;23(2) 138-41.

[51] Lacey C, Cook M, Salzberg M. The neurologist, psychogenic nonepileptic seizures, and borderline personality disorder. Epilepsy Behav. 2007;11(4) 492-8

[52] Bodde NM, Brooks JL, Baker GA, Boon PA, Hendriksen JG, Aldenkamp AP. Psychogenic non-epileptic seizures-diagnostic issues: a critical review. Clin Neurol Neurosurg. 2009;111(1) 1-9.

[53] Galimberti CA, Ratti MT, Murelli R, Marchioni E, Manni R, Tartara A. Patients with psychogenic nonepileptic seizures, alone or epilepsy-associated, share a psychological profile distinct from that of epilepsy patients. J Neurol. 2003;250(3) 338-46.

[54] Kalogjera-Sackellares D, Sackellares JC. Analysis of MMPI patterns in patients with psychogenic pseudoseizures. Seizure. 1997;6(6) 419-27.

[55] Bodde NM, Bartelet DC, Ploegmakers M, Lazeron RH, Aldenkamp AP, Boon PA. MMPI-II personality profiles of patients with psychogenic nonepileptic seizures. Epilepsy Behav. 2011;20(4) 674-80. 
[56] Thompson N, Connelly L, Peltzer J, Nowack WJ, Hamera E, Hunter EE. Psychogenic nonepileptic seizures: a pilot study of a brief educational intervention. Perspect Psychiatr Care. 2013;49(2) 78-83.

[57] Griffith NM, Szaflarski JP, Schefft BK, Isaradisaikul D, Meckler JM, McNally KA, Privitera MD. Relationship between semiology of psychogenic nonepileptic seizures and Minnesota Multiphasic Personality Inventory profile. Epilepsy Behav. 2007;11(1) 105-11.

[58] Reuber M, House AO, Pukrop R, Bauer J, Elger CE. Somatization, dissociation and general psychopathology in patients with psychogenic non-epileptic seizures. Epilepsy Res. 2003;57(2-3) 159-67.

[59] Lawton G, Baker GA, Brown RJ. Comparison of two types of dissociation in epileptic and nonepileptic seizures. Epilepsy Behav. 2008;13(2) 333-6.

[60] Myers L, Fleming M, Lancman M, Perrine K, Lancman M. Stress coping strategies in patients with psychogenic non-epileptic seizures and how they relate to trauma symptoms, alexithymia, anger and mood. Seizure. 2013;22(8) 634-9.

[61] Goldstein LH, Drew C, Mellers J, Mitchell-O'Malley S, Oakley DA. Dissociation, hypnotizability, coping styles and health locus of control: characteristics of pseudoseizure patients. Seizure. 2000;9(5) 314-22.

[62] Frances PL, Baker GA, Appleton PL. Stress and avoidance in Pseudoseizures: testing the assumptions. Epilepsy Res. 1999;34(2-3) 241-9.

[63] Testa SM, Krauss GL, Lesser RP, Brandt J. Stressful life event appraisal and coping in patients with psychogenic seizures and those with epilepsy. Seizure. 2012;21(4) 282-7.

[64] Roberts NA, Burleson MH, Weber DJ, Larson A, Sergeant K, Devine MJ, Vincelette TM, Wang NC. Emotion in psychogenic nonepileptic seizures: responses to affective pictures. Epilepsy Behav. 2012;24(1) 107-15.

[65] Uliaszek AA, Prensky E, Baslet G. Emotion regulation profiles in psychogenic nonepileptic seizures. Epilepsy Behav. 2012;23(3) 364-9.

[66] Skodol AE, Gunderson JG, Pfohl B, Widiger TA, Livesley WJ, Siever LJ. The borderline diagnosis I: psychopathology, comorbidity, and personality structure. Biol Psychiatry. 2002;51(12) 936-50.

[67] Dickinson P, Looper KJ, Groleau D. Patients diagnosed with nonepileptic seizures: their perspectives and experiences. Epilepsy Behav. 2011;20(3) 454-61.

[68] Reuber M, Howlett S, Khan A, Grünewald RA. Non-epileptic seizures and other functional neurological symptoms: predisposing, precipitating, and perpetuating factors. Psychosomatics. 2007;48(3) 230-8.

[69] Baslet G. Psychogenic non-epileptic seizures: a model of their pathogenic mechanism. Seizure. 2011;20(1) 1-13. 
[70] Bautista RE, Gonzales-Salazar W, Ochoa JG. Expanding the theory of symptom modeling in patents with psychogenic nonepileptic seizures. Epilepsy Behav. 2008;13(2) 407-9.

[71] Brown RJ, Bouska JF, Frow A, Kirkby A, Baker GA, Kemp S, Burness C, Reuber M. Emotional dysregulation, alexithymia, and attachment in psychogenic nonepileptic seizures. Epilepsy Behav. 2013;29(1) 178-83.

[72] Walczak TS, Papacostas S, Williams DT, Scheuer ML, Lebowitz N, Notarfrancesco A. Outcome after diagnosis of psychogenic nonepileptic seizures. Epilepsia. 1995;36(11) 1131-7.

[73] Reuber M, Mitchell AJ, Howlett S, Elger CE. Measuring outcome in psychogenic nonepileptic seizures: how relevant is seizure remission? Epilepsia. 2005;46(11) 1788-95.

[74] Kanner AM, Parra J, Frey M, Stebbins G, Pierre-Louis S, Iriarte J. Psychiatric and neurologic predictors of psychogenic pseudoseizure outcome. Neurology. 1999;53(5) 933-8.

[75] Farias ST, Thieman C, Alsaadi TM. Psychogenic nonepileptic seizures: acute change in event frequency after presentation of the diagnosis. Epilepsy Behav. 2003;4(4) 424-9.

[76] Iriarte J, Parra J, Urrestarazu E, Kuyk J. Controversies in the diagnosis and management of psychogenic pseudoseizures. Epilepsy Behav. 2003;4(3) 354-9.

[77] Jirsch JD, Ahmed SN, Maximova K, Gross DW. Recognition of psychogenic nonepileptic seizures diminishes acute care utilization. Epilepsy Behav. 2011;22(2) 304-7.

[78] LaFrance WC Jr, Alper K, Babcock D, Barry JJ, Benbadis S, Caplan R, Gates J, Jacobs M, Kanner A, Martin R, Rundhaugen L, Stewart R, Vert C; NES Treatment Workshop participants. Nonepileptic seizures treatment workshop summary. Epilepsy Behav. 2006;8(3) 451-61.

[79] LaFrance WC Jr, Barry JJ. Update on treatments of psychological nonepileptic seizures. Epilepsy Behav. 2005;7(3) 364-74.

[80] Rusch MD, Morris GL, Allen L, Lathrop L. Psychological Treatment of Nonepileptic Events. Epilepsy Behav. 2001;2(3) 277-283.

[81] Goldstein LH, Chalder T, Chigwedere C, Khondoker MR, Moriarty J, Toone BK, Mellers JD. Cognitive-behavioral therapy for psychogenic nonepileptic seizures: a pilot RCT. Neurology. 2010;74(24) 1986-94.

[82] LaFrance WC Jr, Miller IW, Ryan CE, Blum AS, Solomon DA, Kelley JE, Keitner GI. Cognitive behavioral therapy for psychogenic nonepileptic seizures. Epilepsy Behav. 2009;14(4) 591-6.

[83] Zaroff CM, Myers L, Barr WB, Luciano D, Devinsky O. Group psychoeducation as treatment for psychological nonepileptic seizures. Epilepsy Behav. 2004;5(4) 587-92. 
[84] Prigatano GP, Stonnington CM, Fisher RS. Psychological factors in the genesis and management of nonepileptic seizures: clinical observations. Epilepsy Behav. 2002;3(4) 343-349.

[85] Barry JJ, Wittenberg D, Bullock KD, Michaels JB, Classen CC, Fisher RS. Group therapy for patients with psychogenic nonepileptic seizures: a pilot study. Epilepsy Behav. 2008;13(4) 624-9.

[86] Metin SZ, Ozmen M, Metin B, Talasman S, Yeni SN, Ozkara C. Treatment with group psychotherapy for chronic psychogenic nonepileptic seizures. Epilepsy Behav. 2013;28(1) 91-4.

[87] Ataoglu A, Ozcetin, A, Icmeli C, Ozbulut O. Paradoxical Therapy in Conversion Reaction. J Korean Med Sci 2003;18(4) 581-584.

[88] Moene FC, Spinhoven P, Hoogduin KA, van Dyck R. A randomised controlled clinical trial on the additional effect of hypnosis in a comprehensive treatment programme for in-patients with conversion disorder of the motor type. Psychother Psychosom. 2002;71(2) 66-76.

[89] Barry JJ, Atzman O, Morrell MJ. Discriminating between epileptic and nonepileptic events: the utility of hypnotic seizure induction. Epilepsia. 2000;41(1) 81-4.

[90] Cipriani A, La Ferla T, Furukawa TA, Signoretti A, Nakagawa A, Churchill R, McGuire H, Barbui C. Sertraline versus other antidepressive agents for depression. Cochrane Database Syst Rev. 2010;14 (4).

[91] Ipser JC, Kariuki CM, Stein DJ. Pharmacotherapy for social anxiety disorder: a systematic review. Expert Rev Neurother. 2008;8(2) 235-57.

[92] Voon V, Lang AE. Antidepressant treatment outcomes of psychogenic movement disorder. J Clin Psychiatry. 2005;66(12) 1529-34.

[93] Lieb K, Völlm B, Rücker G, Timmer A, Stoffers JM. Pharmacotherapy for borderline personality disorder: Cochrane systematic review of randomised trials. Br J Psychiatry. 2010;196(1) 4-12.

[94] LaFrance WC Jr, Keitner GI, Papandonatos GD, Blum AS, Machan JT, Ryan CE, Miller IW. Pilot pharmacologic randomized controlled trial for psychogenic nonepileptic seizures. Neurology. 2010;75(13) 1166-73.

[95] Pintor L, Baillés E, Matrai S, Carreño M, Donaire A, Boget T, Setoain X, Rumia J, Bargalló N. Efficiency of venlafaxine in patients with psychogenic nonepileptic seizures and anxiety and/or depressive disorders. J Neuropsychiatry Clin Neurosci. 2010;22(4) 401-8.

[96] Chastan N, Parain D. Psychogenic paralysis and recovery after motor cortex transcranial magnetic stimulation. Mov Disord. 2010;25(10) 1501-4. 
[97] O'Malley PG, Jackson JL, Santoro J, Tomkins G, Balden E, Kroenke K. Antidepressant therapy for unexplained symptoms and symptom syndromes. J Fam Pract. 1999;48(12) 980-90. 